MEDICAL

HYPOTHESIS

\section{Increased vagal tone accounts for the observed immune paralysis in patients with traumatic brain injury}

M. Kox, MSc

J.C. Pompe, MD

P. Pickkers, MD, PhD

C.W. Hoedemaekers, $\mathrm{MD}, \mathrm{PhD}$

A.B. van Vugt, MD, $\mathrm{PhD}$

J.G. van der Hoeven, $\mathrm{MD}, \mathrm{PhD}$

Address correspondence and reprint requests to Dr. Peter Pickkers, Intensive Care Medicine, Radboud University, Nijmegen Medical Centre, Geert Grooteplein 10, 6500 HB Nijmegen, The Netherlands p.pickkers@ic.umcn.nl

\section{ABSTRACT}

Traumatic brain injury (TBI) is a leading cause of death and disability, especially in the younger population. In the acute phase after TBI, patients are more vulnerable to infection, associated with a decreased immune response in vitro. The cause of this immune paralysis is poorly understood. Apart from other neurologic dysfunction, TBI also results in an increase in vagal activity. Recently, the vagus nerve has been demonstrated to exert an anti-inflammatory effect, termed the cholinergic anti-inflammatory pathway. The anti-inflammatory effects of the vagus nerve are mediated by the $\alpha 7$ nicotinic acetylcholine receptor present on macrophages and other cytokineproducing cells. From these observations, we hypothesize that the immune paralysis observed in patients with TBI may, at least in part, result from augmented vagal activity and subsequent sustained effects of the cholinergic anti-inflammatory pathway. This pathway may counteract systemic proinflammation caused by the release of endogenous compounds termed alarmins as a result of tissue trauma. However, sustained activity of this pathway may severely impair the body's ability to combat infection. Since the cholinergic anti-inflammatory pathway can be pharmacologically modulated in humans, it could represent a novel approach to prevent infections in patients with TBI. Neurology ${ }^{\circledR} 2008 ; 70: 480-485$

\section{GLOSSARY}

$\mathbf{H F}=$ high frequency; LF = low frequency; LPS = lipopolysaccharide; TBI = traumatic brain injury; TLR = toll-like receptor.

Traumatic brain injury (TBI) is a leading cause of death and disability in the developed world. In the United States, around 1.5 million people sustain a brain injury annually, of whom approximately 50,000 die., ${ }^{1,2}$ TBI occurs mainly in the younger population, resulting predominantly from motor vehicle accidents, sports injuries, falls, and acts of violence. ${ }^{3}$ Patients with TBI are more vulnerable to infection. As a result, infection is a common and serious complication following TBI. ${ }^{4}$ A recent study reported that especially in the first 20 days after injury, the majority of patients with TBI die of sepsis or pneumonia. ${ }^{5}$ Other workers reported that $77 \%$ of patients developed sepsis or systemic inflammatory response syndrome in the first 7 days following TBI. ${ }^{6}$ It is thought that the phenomenon called post-traumatic immune paralysis is responsible for the increased chance of developing an infection in these patients.

IMMUNE PARALYSIS IN PATIENTS WITH TBI The innate immune response is the first line of defense against invading pathogens. ${ }^{7}$ This tightly regulated system consists of a wide variety of chemokines, cytokines, cell associated receptors, and other mediators orchestrating the initial response to infection. The adaptive immune response is a more specific and focused system comprised of different effector cell types such as B- and T-cells. While these two different systems evolved independently, it has become clear that innate immune signaling plays a critical role in initiating and instructing the adaptive immune response. ${ }^{8}$ Therefore, effects on the innate immune response presumably also alter the adaptive immune response. Although limited, there are experimental data concerning the systemic immune paralysis observed in patients with brain trauma. After severe head injury, decreased T-helper cell activation, attenuated lymphokine-activated killer cell cytotoxicity, and depression of proinflamma-

From the Department of Intensive Care Medicine (M.K., J.C.P., P.P., C.W.H., J.G.v.d.H.) and Department of Surgery, Section Traumatology (J.C.P., A.B.v.V.), Radboud University Nijmegen Medical Centre, The Netherlands.

Disclosure: The authors report no conflicts of interest. 
tory cytokine production (IL-2, IFN- $\gamma$ ), have been reported. ${ }^{9-14}$ Moreover, ex vivo whole blood stimulation with lipopolysaccharide (LPS) shows an attenuated production of proinflammatory cytokines TNF $\alpha$, IL- $1 \beta$, IL- 6 , IL- 8 , IFN- $\gamma$, and IL-12 in polytrauma patients compared to healthy controls. ${ }^{15}$ Another study demonstrated decreased TNF $\alpha$ mRNA levels in human peritoneal macrophages after polytrauma, while the antiinflammatory cytokine IL-10 was upregulated. ${ }^{16}$ Taken together, these results suggest that the early innate immune response, as well as the adaptive immune response, to pathogens is attenuated in patients with TBI. However, the mechanism underlying this immune paralysis following brain injury remains unclear.

THE CNS AND TBI Dysfunction of the CNS has been widely reported in patients with TBI. Many reports focus on the non-autonomic nervous system, such as motor deficits, ${ }^{17,18}$ while others have evaluated the role of the autonomic nervous system after TBI. ${ }^{19-21}$ The autonomic nervous system comprises a collection of afferent and efferent nerve fibers that regulate important vital functions in the body, including blood pressure and heart rate. ${ }^{22,23}$ The autonomic nervous system is composed of two parts, the sympathetic and the parasympathetic (vagal) part. The balance between these two subsystems, the sympathovagal balance, generates the net effect of the autonomic nervous system, of which heart rate is one of the end products. ${ }^{21}$ Heart rate variability reflects the balance between the sympathetic and the parasympathetic parts of the autonomic nervous system, therefore, heart rate variability analysis is extensively used to measure autonomic activity. ${ }^{24}$

MEASUREMENT OF AUTONOMIC NERVOUS SYSTEM ACTIVITY Heart rate variability can be analyzed in the time-domain, yielding normal-tonormal (R-R) intervals or by spectral (frequency domain) analysis of a series of R-R intervals. In the time-domain, heart rate variability is usually expressed as SD of R-R intervals (SDNN) or as the SDNN index (SDNNIDX), which is the average of SDNN per specified interval. ${ }^{25}$ The spectral analysis of R-R intervals is especially useful because a distinction can be made between low frequency (LF) and high frequency (HF) components in heart rate variability, providing information about the interplay of sympathetic and parasympathetic activity. Generally, LF spectral power (range 0.04 to $0.15 \mathrm{~Hz}$ ) reflects sympathetic input while the HF power (range 0.15 to $0.4 \mathrm{~Hz}$ ) represents parasympathetic influence. ${ }^{26,27}$ Therefore, the HF/LF ratio represents a measure of sympathovagal balance. A unique in vivo experiment that illustrates this balance was conducted in patients with an implanted electrical vagus nerve stimulator for the treatment of epilepsy. ${ }^{28}$ In these subjects, HF power and HF/LF ratio were greatly increased when the stimulator was activated, illustrating that these measures are reliable indicators of vagal activity in humans. Nevertheless, caution should be taken when evaluating these parameters because other workers have indicated that parasympathetic outflow and other factors such as baroreceptor activity also influence LF power, thus stating that LF power represents a combination of sympathetic and parasympathetic input. ${ }^{29,30}$ Moreover, HF power can be influenced by factors like respiratory pattern. ${ }^{30}$

\section{HEART RATE VARIABILITY IN PATIENTS WITH} ACUTE TBI Although data are limited, a few human studies have assessed heart rate variability after TBI in the acute phase. An increase in HF/LF ratio was reported in the acute phase after TBI, indicating dominance of parasympathetic activity..$^{20,31}$ In these studies, increased intracranial pressure, often present in acute TBI, has been linked to the high HF/LF ratios observed. ${ }^{20,31}$ Along these lines, patients with acute subarachnoid hemorrhage, which is associated with a rapid increase in intracranial pressure, ${ }^{32}$ displayed significantly increased HF power compared to controls, while LF power did not change. ${ }^{33}$ These results suggest that in patients with TBI, parasympathetic (vagal) activity is augmented, resulting in an increased HF power and increased HF/LF ratio, and that elevated intracranial pressure may play an important role in this process. In addition to the above described association between TBI/increased intracranial pressure and heart rate variability as a measure of vagal tone in patients with TBI, a model of increased intracranial pressure demonstrated a direct link between intracranial pressure and vagal tone. In cats, vagal activity, measured by microneurography, was increased relative to the increase in intracranial pressure induced by inflating a subdural balloon. ${ }^{34}$ This suggests that high intracranial pressure directly influences vagal tone. A potential mechanism behind this phenomenon might be compression of higher vagal nuclei, or the brainstem, leading to vigorous firing of the medulla oblongata, the center where the vagus nerve originates.

VAGAL ACTIVITY AND THE CHOLINERGIC ANTIINFLAMMATORY PATHWAY Experimental evidence in the past several years has demonstrated that activation of the efferent vagus nerve has an 
inhibitory effect on the innate immune response (the cholinergic anti-inflammatory pathway ${ }^{35-37}$ ). Several in vitro studies have demonstrated that pretreatment of cultured human macrophages with the principal vagal neurotransmitter acetylcholine significantly attenuates the LPS-induced release of proinflammatory mediators such as TNF $\alpha$, IL-6, IL-1 $\beta$, IL-18, and HMGB1, while release of the anti-inflammatory cytokine IL-10 was unaffected. ${ }^{38,39}$ Moreover, vagus nerve electrical stimulation attenuates serum TNF $\alpha$ and IL-6 levels in animals after endotoxin administration and prevents the development of shock. ${ }^{38,40-42}$ In contrast, vagotomized animals exhibited elevated levels of proinflammatory cytokines with aggravation of shock. ${ }^{38,43,44}$ In humans, we know of only one study that evaluated inflammatory mediators in patients with a vagus nerve stimulator. ${ }^{45}$ In this study, circulating inflammatory mediators were measured before implantation of the stimulator and after 12 weeks following implantation of the stimulator in a small group of patients with severe depression. After stimulator implantation, the proinflammatory mediators TNF $\alpha$ and IL- 6 were significantly elevated; however, other proinflammatory mediators such as IL-1 and CRP were not. In addition, levels of the anti-inflammatory cytokine TGF- $\beta$ were also significantly increased, which makes it difficult to draw any conclusions regarding the manner in which vagus nerve stimulation modulates the immune status in these patients. Moreover, levels of circulating inflammatory mediators in these patients do not actually reflect the status of the immune response, since no inflammatory stimulus was present.

The anti-inflammatory effect of the vagus nerve is mediated by the $\alpha 7$ nicotinic acetylcholine receptor ( $\alpha 7 \mathrm{nAchR})$ expressed on macrophages and other cytokine-producing cells. ${ }^{42}$ The identification of this receptor stimulated the use of nicotine instead of acetylcholine in studies exploring the anti-inflammatory effect of the vagus nerve because of its higher efficiency and selectivity, and has led to the search for even more selective $\alpha 7 \mathrm{nAchR}$ agonists. ${ }^{39}$ GTS-21, a specific $\alpha 7 \mathrm{nAchR}$ agonist that has already been used in human clinical trials for the treatment of $\mathrm{AD}$, has been studied in a murine pancreatitis model. GTS-21 decreased pancreatitis severity, associated with reduced IL- 6 levels and decreased pancreatic neutrophil accumulation. ${ }^{44}$ Furthermore, CNI-1493, a compound exhibiting systemic antiinflammatory effects currently used in clinical trials for the treatment of Crohn disease, has recently been shown to activate the vagus nerve via a centrally mediated intracerebral effect. ${ }^{46,47}$ CNI-1493 prevented endotoxin-induced shock and attenuated the rise in serum TNF $\alpha$ levels in rats. ${ }^{46,47}$ Inhibitors of $\alpha 7 \mathrm{nAchR}$ have also been identified. Mecamylamine, a drug used in humans for the treatment of hypertension and tobacco addiction, has been utilized in experimental settings and exhibited effects analogous to vagotomy, such as enhanced serum IL-6 levels and augmented severity of inflammation. ${ }^{44}$ The intracellular cascade after $\alpha 7 \mathrm{nAchR}$ activation has been, in part, elucidated by a recent study demonstrating that activation of $\alpha 7 \mathrm{nAchR}$ leads to recruitment and activation of the anti-inflammatory JAK2-STAT3 (Janus kinase-2; signal transducers and activators of transcription-3) cascade. ${ }^{48}$ While studies regarding the cholinergic antiinflammatory pathway have mainly focused on the innate immune system, the adaptive immune response may also be attenuated by vagal outflow because of the vital role the innate immune system plays in initiating the subsequent adaptive immune response.

In addition, apart from the anti-inflammatory effects of the vagus nerve, inflammation can also affect vagal tone. Evaluation of heart rate variability during endotoxic shock in humans demonstrated attenuated variability accompanied by a decrease in total spectral power. ${ }^{49}$ This may represent a negative feedback mechanism to prevent inhibition of the immune response. In this article we focus on the anti-inflammatory effects of the vagus nerve.

The cholinergic anti-inflammatory response represents an exciting new pathway that modulates the innate, and possibly also the adaptive, immune response and provides novel pharmacologic treatment opportunities for situations associated with a disturbed sympathovagal balance.

SUMMARY AND HYPOTHESIS In this report we have discussed three separate observations. 1) The immune response is severely impaired in patients after TBI, and is likely to be associated with the high prevalence of infections in these patients. 2) In the acute phase after TBI, vagal activity is augmented, resulting in a shift in the sympathovagal balance, possibly as a consequence of increased intracranial pressure. 3) Vagal activity has an inhibiting effect on the innate immune response. These observations have led us to a new hypothesis that could explain the immune paralysis observed in patients with TBI. We hypothesize that the impaired immune response in these sub- 
Figure Traumatic brain injury and vagal activity
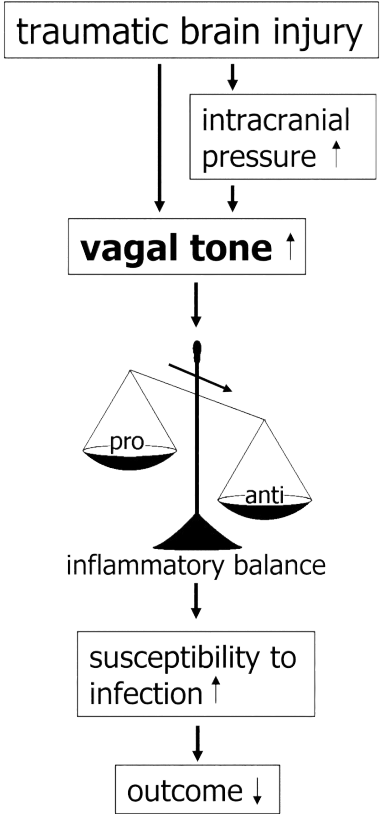

Traumatic brain injury increases vagal tone directly or as a result of elevated intracranial pressure. Subsequently, vagal activity attenuates inflammation via the cholinergic antiinflammatory pathway. As a result, susceptibility toward infections increases, resulting in worse outcome.

jects may, at least in part, result from increased vagal activity and subsequent suppression of the immune response (figure).

DISCUSSION The hypothesis postulated above is based on evidence obtained from studies with different research objects. To our knowledge, no studies are available that test this hypothesis directly. Since the cholinergic anti-inflammatory pathway can be pharmacologically modulated in humans, such treatment in patients with TBI could represent a novel, promising approach to prevent infections in this specific group of patients.

Although elevated intracranial pressure appears to be an important link in the parasympathetic anti-inflammatory response following TBI, other mechanisms have also been suggested. Recently, the role of endogenous mediators in systemic inflammation in the absence of infection ${ }^{50}$ was discussed. Toll-like receptors (TLRs) are well-known for their role in recognition of exogenous pathogens and subsequent triggering of immune responses. Excessive or inappropriate activation of TLRs can lead to systemic inflammation and shock, similar to that observed in septic patients. In addition to recognizing outside invaders, TLRs, as well as other receptors, also recognize endogenous damage signals termed alarmins, such as heat-shock proteins and
HMGB1. Tissue trauma, for instance resulting from TBI, elicits release of these damage signals. ${ }^{51-53}$ Consequently, trauma can trigger the immune response and this could explain the systemic inflammatory reaction in the absence of infection often observed in these patients. An increase in vagal activity may counteract this mechanism by attenuating the release of endogenous inflammatory mediators. In this context, it is noteworthy that ex vivo treatment of human monocytes with nicotine (stimulation of the cholinergic anti-inflammatory pathway) resulted in downregulation of TLR4 expression in human monocytes. ${ }^{54}$ This observation may also explain the attenuated production of proinflammatory cytokines in blood of trauma patients that was stimulated ex vivo with LPS, the primary ligand for TLR $4 .{ }^{15}$ In this prospect, increased vagal activity may represent a negative feedback mechanism counteracting the massive systemic proinflammatory response. This notion is supported by animal studies in which increased vagal activity resulted in attenuation of inflammation, prevention of development of shock, and decreased mortality after experimental inflammation. ${ }^{38,39,44}$ In this view, the resultant and sustained immune paralysis is merely a side-effect of the negative feedback loop. However, the animal studies mentioned before have all been performed using models of sterile inflammation. In animal experiments using live microbial sepsis, activation of the cholinergic anti-inflammatory pathway resulted in worsened survival, impaired migration of neutrophils to the inflamed area, and increased outgrowth of bacteria. ${ }^{40,43,55}$ Moreover, human data on heart rate variability in the acute phase after TBI indicates that increased HF/LF ratios are associated with poor outcome and higher mortality. ${ }^{31,56,57}$ These results suggest that increased vagal activity is beneficial in sterile inflammation induced by LPS or chemical compounds that evoke inflammation, but may impair the body's ability to combat an infection with live bacteria.

In contrast to aforementioned studies, also a decreased HF power and decreased HF/LF ratios have been reported in patients with TBI. ${ }^{19,21,58}$ However, these studies evaluated patients in the post-acute (chronic) phase of TBI ( $>30$ days). Along these lines, patients in the chronic phase of subarachnoid hemorrhage demonstrated similar HF/LF ratios compared to control subjects, while $\mathrm{HF} / \mathrm{LF}$ ratios were increased in the acute phase, as discussed before. ${ }^{33}$ In the chronic phase of TBI or subarachnoid hemorrhage, patients usually do 
not have an increased intracranial pressure, possibly explaining the absence of increased vagal activity. Moreover, a potential explanation for decreased vagal output in the chronic phase of TBI may be damage to the brainstem and medulla oblongata resulting in impaired activity of the vagus nerve. In the acute phase of TBI, this effect may be overwhelmed by vigorous firing as a consequence of the compression of the brainstem. One study in a very acute setting (immediately after admission to the intensive care unit one 5-minute ECG was recorded) also reported decreased vagal activity and lower HF/LF ratios, indicating sympathetic dominance. ${ }^{59}$ However, in this very acute setting, elevated intracranial pressure has probably not developed yet. Thus, time after injury appears to be a very important factor in autonomic dysfunction.

Taken together, we believe that our hypothesis may, at least in part, explain the immune paralysis observed in the first phase following TBI. Since increased vagal tone is associated with increased mortality and poor outcome in patients with TBI, intervening in the cholinergic antiinflammatory pathway could be of potential benefit to these patients. This possibility warrants further research to elucidate the mechanism of immune paralysis in patients with TBI.

Received December 28, 2006. Accepted in final form May 18, 2007.

\section{REFERENCES}

1. Sosin DM, Sniezek JE, Waxweiler RJ. Trends in death associated with traumatic brain injury, 1979 through 1992. Success and failure. JAMA 1995;273:1778-1780.

2. Sosin DM, Sniezek JE, Thurman DJ. Incidence of mild and moderate brain injury in the United States, 1991. Brain Inj 1996;10:47-54.

3. Consensus conference. Rehabilitation of persons with traumatic brain injury. NIH Consensus Development Panel on Rehabilitation of Persons With Traumatic Brain Injury. JAMA 1999;282:974-983.

4. Boddie DE, Currie DG, Eremin O, Heys SD. Immune suppression and isolated severe head injury: a significant clinical problem. Br J Neurosurg 2003;17:405-417.

5. Rondina C, Videtta W, Petroni G, et al. Mortality and morbidity from moderate to severe traumatic brain injury in Argentina. J Head Trauma Rehabil 2005; Jul 20: 368-376.

6. O'Connor E, Venkatesh B, Mashongonyika C, Lipman J, Hall J, Thomas P. Serum procalcitonin and C-reactive protein as markers of sepsis and outcome in patients with neurotrauma and subarachnoid haemorrhage. Anaesth Intensive Care 2004;32:465-470.

7. Delves PJ, Roitt IM. The immune system. First of two parts. N Engl J Med 2000;343:37-49.
8. Dempsey PW, Vaidya SA, Cheng G. The art of war: innate and adaptive immune responses. Cell Mol Life Sci 2003;Dec 60:2604-2621.

9. Quattrocchi KB, Frank EH, Miller CH, et al. Suppression of cellular immune activity following severe head injury. J Neurotrauma 1990;7:77-87.

10. Quattrocchi KB, Frank EH, Miller CH, Amin A, Issel BW, Wagner FC Jr. Impairment of helper T-cell function and lymphokine-activated killer cytotoxicity following severe head injury. J Neurosurg 1991;75:766773.

11. Quattrocchi KB, Frank EH, Miller CH, Dull ST, Howard RR, Wagner FC Jr. Severe head injury: effect upon cellular immune function. Neurol Res 1991;13: $13-20$.

12. Quattrocchi KB, Issel BW, Miller CH, Frank EH, Wagner FC Jr . Impairment of helper T-cell function following severe head injury. J Neurotrauma 1992;9:1-9.

13. Quattrocchi KB, Miller CH, Wagner FC Jr, et al. Cellmediated immunity in severely head-injured patients: the role of suppressor lymphocytes and serum factors. J Neurosurg 1992;Nov 77:694-699.

14. Miller CH, Quattrocchi KB, Frank EH, Issel BW, Wagner FC Jr. Humoral and cellular immunity following severe head injury: review and current investigations. Neurol Res 1991;13:117-124.

15. Keel M, Schregenberger N, Steckholzer U, et al. Endotoxin tolerance after severe injury and its regulatory mechanisms. J Trauma 1996;41:430-437.

16. Hauser CJ, Lagoo S, Lagoo A, et al. Tumor necrosis factor alpha gene expression in human peritoneal macrophages is suppressed by extra-abdominal trauma. Arch Surg 1995;130:1186-1191.

17. Stein DG, Hoffman SW. Concepts of CNS plasticity in the context of brain damage and repair. J Head Trauma Rehabil 2003;18:317-341.

18. Gaetz M. The neurophysiology of brain injury. Clin Neurophysiol 2004;115:4-18.

19. Baguley IJ, Heriseanu RE, Felmingham KL, Cameron ID. Dysautonomia and heart rate variability following severe traumatic brain injury. Brain Inj 2006;20:437444.

20. Biswas AK, Scott WA, Sommerauer JF, Luckett PM. Heart rate variability after acute traumatic brain injury in children. Crit Care Med 2000;28:3907-3912.

21. Keren O, Yupatov S, Radai MM, et al. Heart rate variability (HRV) of patients with traumatic brain injury (TBI) during the post-insult sub-acute period. Brain Inj 2005;19:605-611.

22. Freeman JV, Dewey FE, Hadley DM, Myers J, Froelicher VF. Autonomic nervous system interaction with the cardiovascular system during exercise. Prog Cardiovasc Dis 2006;48:342-362.

23. Guyenet PG. The sympathetic control of blood pressure. Nat Rev Neurosci 2006;7:335-346.

24. van Ravenswaaij-Arts CM, Kollee LA, Hopman JC, Stoelinga GB, van Geijn HP. Heart rate variability. Ann Intern Med 1993;118:436-447.

25. Buchman TG, Stein PK, Goldstein B. Heart rate variability in critical illness and critical care. Curr Opin Crit Care 2002;8:311-315.

26. Montano N, Ruscone TG, Porta A, Lombardi F, Pagani M, Malliani A. Power spectrum analysis of heart rate variability to assess the changes in sympathovagal 
balance during graded orthostatic tilt. Circulation 1994;90:1826-1831.

27. Rimoldi O, Pierini S, Ferrari A, Cerutti S, Pagani M, Malliani A. Analysis of short-term oscillations of R-R and arterial pressure in conscious dogs. Am J Physiol 1990;258:H967-H976.

28. Kamath MV, Upton AR, Talalla A, Fallen EL. Effect of vagal nerve electrostimulation on the power spectrum of heart rate variability in man. Pacing Clin Electrophysiol 1992;15:235-243.

29. Pomeranz B, Macaulay RJ, Caudill MA, et al. Assessment of autonomic function in humans by heart rate spectral analysis. Am J Physiol 1985;248:H151-H153.

30. Ori Z, Monir G, Weiss J, Sayhouni X, Singer DH. Heart rate variability. Frequency domain analysis. Cardiol Clin 1992;10:499-537.

31. Winchell RJ, Hoyt DB. Analysis of heart-rate variability: a noninvasive predictor of death and poor outcome in patients with severe head injury. J Trauma 1997;43: 927-933.

32. Voldby B. Pathophysiology of subarachnoid haemorrhage. Experimental and clinical data. Acta Neurochir Suppl (Wien) 1988;45:1-6.

33. Kawahara E, Ikeda S, Miyahara Y, Kohno S. Role of autonomic nervous dysfunction in electrocardiographic abnormalities and cardiac injury in patients with acute subarachnoid hemorrhage. Circ J 2003;67: 753-756.

34. Matsuura S, Sakamoto H, Hayashida Y, Kuno M. Efferent discharges of sympathetic and parasympathetic nerve fibers during increased intracranial pressure in anesthetized cats in the absence and presence of pressor response. Brain Res 1984;305:291-301.

35. Pavlov VA, Tracey KJ. Controlling inflammation: the cholinergic anti-inflammatory pathway. Biochem Soc Trans 2006;34:1037-1040.

36. Pavlov VA, Tracey KJ. The cholinergic antiinflammatory pathway. Brain Behav Immun 2005;19: 493-499.

37. Pavlov VA, Wang H, Czura CJ, Friedman SG, Tracey KJ. The cholinergic anti-inflammatory pathway: a missing link in neuroimmunomodulation. Mol Med 2003;9:125-134.

38. Borovikova LV, Ivanova S, Zhang $M$, et al. Vagus nerve stimulation attenuates the systemic inflammatory response to endotoxin. Nature 2000;405:458-462.

39. Wang $\mathrm{H}$, Liao $\mathrm{H}$, Ochani $\mathrm{M}$, et al. Cholinergic agonists inhibit HMGB1 release and improve survival in experimental sepsis. Nat Med 2004;10:1216-1221.

40. van Westerloo DJ, Giebelen IA, Florquin S, et al. The cholinergic anti-inflammatory pathway regulates the host response during septic peritonitis. J Infect Dis 2005;191:2138-2148.

41. van Westerloo DJ, Giebelen IA, Meijers JC, et al. Vagus nerve stimulation inhibits activation of coagulation and fibrinolysis during endotoxemia in rats. J Thromb Haemost 2006;4:1997-2002.

42. Wang $\mathrm{H}, \mathrm{Yu} \mathrm{M}$, Ochani $\mathrm{M}$, et al. Nicotinic acetylcholine receptor alpha7 subunit is an essential regulator of inflammation. Nature 2003;421:384-388.

43. Kessler W, Traeger T, Westerholt A, et al. The vagal nerve as a link between the nervous and immune sys- tem in the instance of polymicrobial sepsis. Langenbecks Arch Surg 2006;391:83-87.

44. van Westerloo DJ, Giebelen IA, Florquin S, et al. The vagus nerve and nicotinic receptors modulate experimental pancreatitis severity in mice. Gastroenterology 2006;130:1822-1830.

45. Corcoran C, Connor TJ, O'Keane V, Garland MR. The effects of vagus nerve stimulation on pro- and antiinflammatory cytokines in humans: a preliminary report. Neuroimmunomodulation 2005;12:307-309.

46. Bernik TR, Friedman SG, Ochani M, et al. Pharmacological stimulation of the cholinergic antiinflammatory pathway. J Exp Med 2002;195:781-788.

47. Borovikova LV, Ivanova S, Nardi D, et al. Role of vagus nerve signaling in CNI-1493-mediated suppression of acute inflammation. Auton Neurosci 2000;85:141147.

48. de Jonge WJ, van der Zanden EP et al. The FO Stimulation of the vagus nerve attenuates macrophage activation by activating the Jak2-STAT3 signaling pathway. Nat Immunol 2005;6:844-851.

49. Godin PJ, Fleisher LA, Eidsath A, et al. Experimental human endotoxemia increases cardiac regularity: results from a prospective, randomized, crossover trial. Crit Care Med 1996;24:1117-1124.

50. Zedler S, Faist E. The impact of endogenous triggers on trauma-associated inflammation. Curr Opin Crit Care 2006;12:595-601.

51. da Rocha AB, Zanoni C, de Freitas GR, et al. Serum Hsp70 as an early predictor of fatal outcome after severe traumatic brain injury in males. J Neurotrauma 2005;22:966-977.

52. Lai Y, Stange C, Wisniewski SR, et al. Mitochondrial heat shock protein 60 is increased in cerebrospinal fluid following pediatric traumatic brain injury. Dev Neurosci 2006;28:336-341.

53. Scaffidi P, Misteli T, Bianchi ME. Release of chromatin protein HMGB1 by necrotic cells triggers inflammation. Nature 2002;418:191-195.

54. Hamano R, Takahashi HK, Iwagaki H, Yoshino T, Nishibori M, Tanaka N. Stimulation of alpha7 nicotinic acetylcholine receptor inhibits CD14 and the tolllike receptor 4 expression in human monocytes. Shock 2006;26:358-364.

55. Huston JM, Ochani M, Rosas-Ballina M, et al. Splenectomy inactivates the cholinergic antiinflammatory pathway during lethal endotoxemia and polymicrobial sepsis. J Exp Med 2006;203:1623-1628.

56. Cooke WH, Salinas J, Convertino VA, et al. Heart rate variability and its association with mortality in prehospital trauma patients. J Trauma 2006;60:363-370.

57. Winchell RJ, Hoyt DB. Spectral analysis of heart rate variability in the ICU: a measure of autonomic function. J Surg Res 1996;63:11-16.

58. King ML, Lichtman SW, Seliger G, Ehert FA, Steinberg JS. Heart-rate variability in chronic traumatic brain injury. Brain Inj 1997;11:445-453.

59. Su CF, Kuo TB, Kuo JS, Lai HY, Chen HI. Sympathetic and parasympathetic activities evaluated by heart-rate variability in head injury of various severities. Clin Neurophysiol 2005;116:1273-1279. 